\title{
Reading Instructions In African Schools' Transition To English Medium Education: Matters Emerging From Classroom Observations
}

\author{
Masello Hellen Phajane, Preller Street, University of South Africa, Pretoria, South Africa, \\ Phajamh@unisa.ac.za
}

\begin{abstract}
Reading ability is currently a matter of great concern in South Africa. Students in this country have difficulty in reading and writing and are often functionally uneducated. This study focuses on the beliefs, experiences and practices of teachers of reading in English to second language students in Grade 4. Grade 4 is the transitional grade from mother tongue to English as the medium of instruction. The shift to English makes teaching reading in that language especially challenging. The study used a qualitative method and is structured according to the case study mode of enquiry, with the target respondents comprising Grade 4 teachers. Classroom observation, interviews and document analysis were used as means of collecting data. The main findings revealed that beliefs and experience had an impact on the way in which reading was taught in this study. It emerged that the teachers' childhood experiences of literacy and learning to read are maintained in their beliefs, their attitudes, their basic conceptualization of reading and their current practices, all of which directly affect the students in their classrooms. Recommendations arising from research indicate possible areas for improvement in the teaching of reading and offer guidelines to help teachers cope with the challenge.
\end{abstract}

Keywords: Classroom instruction; Language skills; Learning difficulties; Reading forms; Second language

Received: 07.12.2020 Accepted: 18.01.2021 $\quad$ Published: 03.02.2021

\section{INTRODUCTION}

Reading is essential to success in any society and the ability to read is highly valued and important for both social and economic advancement (Coxhead, 2016). Similarly, reading forms the basis for all language skills, particularly writing, because the ability to write depends on the ability to read and what is written can only make meaning if it can be read. Therefore, reading and writing are mutually supportive and are thus inseparable. Reading is one of the four language skills in which students need to be versed in their earliest years in formal schooling since it builds the foundation for formal learning in school (Coxhead, 2016). It is therefore important to remember that if students do not acquire this skill in the foundation phase, they will struggle to catch on even with the help of remedial teaching and they will not progress well at school (Phajane, 2017).

It is no news that reading problems plague our country (The International Reading Association, (IRA) 2009). The media have informed us of this over and over again. Most people, even those whose children are facing the horror of reading difficulties are totally unaware of the fact that the problem is not limited to 5 percent, 10 percent or even 20 percent of the population. The shocking fact is that approximately 40 percent of all children perfectly healthy, normal children experience difficulties in learning to read (The International Reading Association, (IRA) 2009). Sadly, all our assessments of how well our children read reveal that a shockingly high number cannot read at the appropriate grade and age level (Statistics South Africa (Stats SA), 2016).

In a country like South Africa (SA) that has fought so long and hard for its freedom, this is an untenable situation that demands urgent attention from all of us. The ability to read and write is not a privilege; it is a right, enshrined in our Constitution (Department of Education, (DoE) 2012). Combating illiteracy is a task that simply cannot be tackled by one sector of the community; all stakeholders in this country must get stuck in, (Statistics South Africa (Stats SA), (2016).

The International Reading Association, (IRA) (2009:154), stated: "every child deserves excellent reading teachers, because teachers make a difference in children's reading achievement and motivation to read". Here, the focus is on the power of the teacher, not the power of a programme used by a teacher (Makalela, 2010). Programmes can help or hinder a teacher's instruction, but exemplary teachers know how to tailor the available programmes to the unique strengths and needs of their students. Being an exemplary teacher of literacy is not an easy task. Exemplary teachers realise how important each minute 
of each day is, in helping students learn to read and write. They also reflect on their practice and learn from mistakes (Maluch, Kempert, Neumann \& Stanat, 2015).

\section{LITERATURE REVIEW}

Children need to develop a strong reading skill in their second language because in Grade 4 they are expected to make the transition to learning through the medium of English, their textbooks are in English and therefore competent reading skills in this language are very important. In order to understand the language policy better, one has to look at its background, intentions and goals; it is the language policy that determines the language in which students in Grade 4 are taught.

\section{Educational Language Policy in South Africa}

In South Africa, the majority of students (over $80 \%$ ) speaks mother tongue (African language), but at Grade 4 level, learns through the medium of English, which enjoys less than a 10\% inherent speaker population (King \& Lanza, 2017); Schwartz (2018). Schooling in the Foundation Phase (Grade R-3) is in the Home Language before transitioning to English (for the majority of students) in Grade 4 UMALUSI, (2014). The Language in Education Policy (LiEP) of 1997 makes provision for students to elect the Language of Learning and Teaching (LoLT) at Grade 4 (Department of Basic Education (DBE), Republic of South Africa, 2010) and in most cases the elected language and the language offered by the school as Language of Learning and Teaching (LoLT) is mother tongue (Setswana).

According to Sibanda \& Baxen (2016), this is typical of the African continent particularly in SubSaharan Africa, where, despite the language diversity, most students school through the medium of English, a colonial language. This underscores the need for student competence in Setswana by end of Grade 3 to effectively learn in the language at Grade 4. Caporal-Ebersold, (2018), suggests that the sudden transition from using an African language in the Foundation Phase (FP) to using English as the Language of Learning and Teaching (LoLT) in Grade 4 sets students up for failure National Education Evaluation and Development Unit (NEEDU), 2014).

\section{Languages with High and Low Status in South Africa}

Makalela \& Fakude (2014), claim that although South Africa has a multilingual policy that recognizes many official languages, not all the languages are equal in status. The status of African languages remains due to lack of policy implementation at school and tertiary education level as well as failure of politicians to use these languages during official presentations. African languages therefore remain languages used at home as well as for religious purposes only (Caporal-Ebersold, Eloise \& Young, 2016). Caporal-Ebersold (2018), argues that the use of languages in a multilingual country, is mainly based on their utility value in various social structures (e.g. courts, education, economy and politics) and the opportunities offered to those people who can speak them, languages are evaluated differently National Education Evaluation and Development Unit, (NEEDU) (2014).

The languages used for official purposes give the people who are first language speakers of these languages more power and status despite the fact that the speakers of these official languages are very few (Otto, 2014). In South Africa, for example, English is of the official languages and a medium of instruction although the majority of black people do not have proficiency in the language. English is therefore regarded as a majority language and African language speakers are minority language speakers because their languages do not enjoy the dominance status National Education Evaluation and Development Unit (NEEDU), 2014).

Diemer, (2016), contends that there are movements in various countries which are fighting for the use of children's first language as medium of instruction in order to cultivate literacy skills among students from disadvantaged backgrounds. The new language in education policy in South Africa also recognises the important role that indigenous languages should play in education. However, there appears to be a lack of will to implement the language in education policy (Manyike, 2017).

\section{Problems in Implementing the Language Policy in South Africa}

Many teachers before independence were used to speaking and teaching in English and Afrikaans. After independence, they switched over to English. Makalela and Fakude (2014), argue that this switch over was a stressful move and certainly affected the entire education system in the country. This view is supported by Modisaotsile (2012), who contends that this change led to serious problems in formal education and in other domains where people felt marginalized and second-class citizens because they were not competent in the official language UMALUSI, (2014). 
These points clarify why the switch to English medium at independence proved to be a major test for many of the country's teachers, whose English proficiency was insufficient to enable them to cope with teaching in a new language (Manyike, 2017). Many teachers were faced with the situation where contact with and exposure to English in any form was limited both for themselves and their students, thus restricting English to the unreal classroom environment Caporal-Ebersold, Eloise and Young (2016). The same concern was expressed in the research on English Language Proficiency of South African Teachers, Progress in International Reading Literacy Study (PIRLS) (2011:132):

At independence in 1994 came the implementation of the decision to use English as the official medium of instruction from Grade 4 onwards, with little time for preparation, almost all of South African's teachers had to adjust to teaching in and through English a language in which they had and in many cases still have a low level of proficiency.

\section{Theories Of Reading}

The teaching of reading is underpinned by different reading theories formulated by different researchers and scholars. In order to have a broader understanding of the teaching of reading, I now explore different theories of reading. In this section I start by looking at how mother tongue language development forms the basis for learning to read in a second language. On this note, Bonacina-Pugh (2017), avows that it is the students' first language that provides a rich cognitive preparation for second language learning. BonacinaPugh (2017), further argues that it is the skills acquired in the first language that provide for an easy transition to the second language medium. This view is supported by Cummins, (2012), who describes the relationship between people's first language and second language. He contends that language students have a Common Underlying Proficiency (CUP) that supports second language learning by transferring skills from the first to the second language (Cummins, 2012).

Cummins's, (2012), linguistic theory highlights two important categories of language competency for learning. Firstly, Basic Interpersonal Communication Skills (BICS), which is everyday language and is context embedded. Secondly, there is the Cognitive Academic Language Proficiency (CALP). This is defined as the basis for a child to cope with the academic demands placed upon him/her in various subjects. Cognitive Academic Language Proficiency (CALP), is said to be a higher-level language skill required for literacy and cognitively demanding content, for example, reading about an unfamiliar subject (Cummins, 2012). Cummins theorizes that Cognitive Academic Language Proficiency (CALP), developed in the first language and transferred to the second helps support second language literacy acquisition. He further argues that if children do not develop a certain level of Cognitive Academic Language Proficiency (CALP), in their first language, the benefit will not be transferred to the second language. Therefore, teaching children to read in their first language helps them to learn to read in their second language (Manyike, 2017).

A similar theory of reading is advanced by Schwartz (2018), drawing on Vygotsky's notion of spontaneous and scientific concepts. According to Vygotsky (1995), spontaneous concepts are concepts learnt from one's home environment whereas scientific concepts are concepts learnt from school. Bonacina-Pugh, (2017), claims that spontaneous concepts are learned unconsciously through every day experiences using basic interpersonal communication skills, whilst scientific concepts are schooled concepts, taught or mediated through cognitive academic language. Unfortunately for the South African child, the ground for spontaneous learning of a second language is bare because the experiences are literally absent. As indicated earlier, teachers are ill prepared to teach in English as a medium of instruction. In this respect, it is very difficult for the students on the receiving end to acquire the intended language skills (Sibanda \& Baxen, 2016). In essence therefore, when teaching reading in the second language, one has to look at the totality of what is involved when learning to read.

Grade 4 presents a particular challenge for students and teachers with regard to reading as it is the year in which children shift from the mother tongue to English as the medium of instruction. This is challenging because children are used to learning through their mother tongue in Grades 1-3 and many of them speak English as a third or fourth language. Reading presents a special challenge because from Grade 4 onwards, all learning materials are written in English and students must be fluent readers in this language in order to succeed at school.

\section{METHODS}

This study employed qualitative research method. The research was conducted in the interpretive paradigm. This approach is appropriate for this research because it gives me an opportunity to understand teachers' practices in teaching reading in English in Grade 4, Mitropolitski, (2015: 95) sees:

... interpretive research as a category of empirical research. Interpretive research needs to have some of empirical elements to it in order to counter threats to validity. This is clearly found in structured data from 
which interpretation and understanding can be generated. Therefore, the researcher tries to describe, interpret and explain what is happening without making any value judgments or trying to induce any change.

This research has an empirical dimension in that I investigate what actually happens when two teachers teach reading in English in Grade 4. My intention is to interpret their actions in relation to their beliefs about teaching reading. I used semi-structured interview questions, classroom observations and document analysis in collecting data from the two teachers I selected for my study. I interviewed both the teachers in English. The interviews were tape-recorded and transcribed. I looked for patterns and I categorized them into themes. For ethical reasons, the two teachers and their schools were given pseudonyms (Mitropolitski, 2015).

\section{RESULTS}

The observations focused on two things namely, inside the classrooms (resources, teacher student interaction) and most importantly on the beliefs which inform their practice in the teaching of reading. Observations were conducted to establish beliefs which inform their practice to teach reading in the home language and to observe other factors that could have influenced the poor reading of children. The following are the outcomes:

The section gives the reader an overview of how students are taught to read in two South African foundation phase classrooms. It focuses on the description of teachers' lessons, interviews and document analysis. Before I describe the teacher's lessons, I will explore their understanding of the concept of teaching reading and how they were trained in teaching reading in Grade 4. I will also explore how students use library books to enhance their reading skills.

In the next section I describe the teachers' reading lessons and thereafter give an analysis of both lessons. The comparison of lessons and the approaches used by these two teachers will be discussed below.

\section{Teacher A's Reading Lessons at School C}

The students in Teacher A's class were seated according to groups in the English reading class. Each group consisted of six to seven students. Teacher A mixed the groups according to abilities so that those who could read could help those who were struggling to read.

Teacher A's lesson was on the theme about UBUNTU from Life Orientation, which she was teaching according to the curriculum. She plans her reading lessons for a week. The topic was a story about a Lion and Mouse taken from the class reader. During the first reading lesson, each group took it in turns to read aloud together to the rest of the class. Teacher A said to the class:

Now pay attention, we are going to read in groups. I want group one to start and everyone should look in your reader.

Then group 1 started to read as follows:

Once upon a time there was a lion sleeping in a forest. A mouse started playing on it. The lion was disturbed and arose from his sleep. It caught up the mouse angrily and tried to crush it to death. Then the mouse prayed the lion to leave him off and assured that it would help him when it needed.

Then group 2 started where group 1 left off:

The lion laughed at it and let him off. One day the lion was caught in a net spread by a hunter. It roared and tried to escape but in vain. The mouse heard the lion's roaring and came there. It started cutting the net with its teeth. The lion escaped and thanked the mouse.

Each group read aloud until everyone had taken a turn. Sometimes the teacher read with the groups to help them where they could not manage the text. Teacher A used phonics when a student was having difficulty with the pronunciation of a word; she would point at the first letter for the student to sound till he/she pronounced the word correctly. Afterwards the teacher picked out the following vocabulary words from the story: angrily, assured, caught, crush, death, forest.

These words were written on the chalkboard. Teacher A pointed at the first word and asked students to read the word aloud. All the students read the word correctly and simultaneously. Then she asked the students, the meaning of each word and use it in a sentence. One of the students answered, $I$ caught a bird sitting on a tree. Then the teacher said, there are many other things, you can catch. Another student responded; my mother caught a chicken running in the yard. The teacher went to the next word, until all the words were dealt with. In Teacher A's class students used dictionaries when they were needed to look up the meaning of a word.

Teacher A's second lesson was on reading comprehension. She gave the students an extract from a non-fiction text about Daniel the Hero Bravo on a photocopied worksheet, which each child pasted in his/her exercise book. She began her lesson by reading the questions to the students so that they should 
found answers from the text. The questions were as follows: In what country was Daniel Hero Bravo born? What was his father's work? When did he start writing books? How many did he write?

Teacher A gave instructions to her students as follows: I want you to skim and scan through the text for five minutes and write the answers in your exercise books. Students were told to do this exercise silently and not to disturb others. Within the given time some of the students were finished with the exercise. Those who finished earlier went to the reading corner to pick up a book to read. This was a routine in her class, whenever students were finished with their work, they went silently to the reading corner to pick up a book and read.

In the third lesson, Teacher A told the students to pick out doing words from the story which was photocopied for students again to paste in their exercise books. She told students that they are going to read the story individually as they are going to search for doing words from the given passage. She pointed at one student to read the first paragraph and the student read as follows:

Seboka lived with her family on a hillside near a river. During the week, her parents went in town nearby. Seboka walked to school on the other side of the hill with her friends. In the morning, her grandmother looked after her younger brother, Philly. In the afternoon, after doing her homework, Seboka looked after him.

After reading the paragraph the teacher told the students to underline the verbs in the paragraph. Then a second student read the second paragraph and they underlined the doing verbs from it, until students had completed underlining the verbs from the passage.

\section{Teacher B's Reading Lessons at School D}

The reading arrangements in Teacher B's class were similar to Teacher A's class as Teacher B's students were also seated in groups. Teacher B's first reading lesson was from a newspaper article from the South African newspaper called Sowetan with the headline entitled 'A furious blade attack flickered by an overpriced amount of money. She was also dealing with the theme from the Life Orientation syllabus about UBUNTU; the social environment on current issues and events in the area and she also planned her reading lessons for a week. She started her lesson with the phonics dealing with the following vowel sound: -arsounds: are, arm, arts, area, arrest, ark, dark and arrival.

These sounds were taught at the beginning of the lesson and were written on a chart. The teacher pointed to the sounds and students sounded them. These words were drilled for three days during my observations. When asked during the stimulated recall why she used these sounds, this is what she said:

"I use phonics because they help students to read. Phonics is important because students look at the letter and sound." She went on to say after finishing with the lesson, "I will paste the chart on the wall for them to look, read and sound the words every day and they will know the words incidentally."

After teaching the phonics, Teacher B focused on the following vocabulary words from the text: situation, serious, apparently, attack, denial, suspicious, church, examining and capture. These words were written on flash cards and were put upside down so that the students could not deliberately choose a simple word from which to construct a sentence. One student in her class volunteered himself and picked the word 'church,' he constructed a sentence as follows: My grandmother is in the church.

The same pattern was used with all the words. One student picked the word 'apparently;' she struggled with the pronunciation and the teacher helped her. But when it came to the meaning and putting it into a sentence, the student failed. Then the teacher told the class that she would look up the word in the dictionary as she was not quite sure of the meaning of the word herself.

After all the vocabulary words were put into sentences, there was a class activity similar to Teacher A's in which students read aloud from group to group. However, in this case, Teacher B sometimes asked individuals and sometimes the whole group to read aloud. Teacher B pointed at the first group to read the first paragraph and it was read as follows:

A 58-year old woman, Mercia Marton, is in a serious condition in the Intensive Care Unit of the Steve Biko Government Hospital after her son allegedly attacked her with a blade. Local police commander Sergeant Malebana told the South Africans that the attack was apparently prompted by the woman's refusal to hand over the money that her son had given to her for safekeeping.

After the first group finished reading the first paragraph, the second group followed where the first group had left off. The process of reading in groups continued up to the last group in the class. In her second and third lessons the same lesson content was repeated. The same phonic sounds were dealt with at the beginning of the lesson although new vocabulary words were taught, for example, chopped, suspicious, protection and seemingly. When asked why the same lesson had been taught for three days, the teacher said: The reading lesson is having big words to understand, and the text seemed difficult for the students. So, I go over it slowly for a week so that students can understand current issues in our area.

\section{Analysis of Teachers' Reading Lessons}


Looking at both teachers' lessons, it is interesting to note that Teacher A's students were able to read fluently and with understanding, the evidence being that in all the three lessons I observed, students were able to answer questions on each task they were given. Whereas in Teacher B's class students struggled to read. When asked during the stimulated recall why most of her students could not read fluently, Teacher B answered that it was the background of the students as they were used to mother tongue and to switch straight to English was a problem.

Teacher B commented that fluency sometimes depended on the story. If the story was simple, they could understand it easily, but if it had some difficult words they would struggle to read. Another important factor with regard to fluency was that Teacher B was expecting her students to read a very difficult text, which she had selected for them. Therefore, it is not surprising that they could not read it fluently and with understanding.

Another problematic issue in Teacher B's lesson was the way in which she taught -ar sounds. The following words were chosen from the passage to illustrate this sound: area, arrest and arrival. However, none of these three words contain the -ar sound as in 'farm'. This suggests that the teacher might have a shallow understanding of English phonology herself. She did not seem to understand that she needed to focus on the sounds rather than the spelling of the words. Furthermore, the vocabulary words such as suspect, condition, allegedly and investigating were too difficult for children at this level.

The two teachers have differences and similarities in their approach to teaching reading in Grade 4 and this might be that their early reading exposure influences the way they teach. Below is the discussion about the comparison of their approaches in teaching reading.

\section{Teachers' Perceptions on the Concepts of Teaching Reading}

Another issue that emerged from the data is teachers' perceptions of the teaching of reading. My participants each attached a different meaning to the teaching of reading. The findings reveal that teachers' childhood experiences of literacy affect their beliefs and attitudes, their conceptualization of reading and their current practices. This was reflected in their lesson presentations. Teacher A conceptualized the teaching of reading as enabling students to read for understanding. Her reading lessons showed a great difference from those of Teacher B whose concept of teaching reading meant, reading is just reading whether with understanding or not. As long as students can open their mouth to read, that is reading.

Furthermore, Teacher A is teaching in a context which supports her perception of reading for understanding. She follows a school policy which stresses that students should be able to read with understanding. The whole school spends twenty minutes reading every morning, Monday through Friday, before they start with any other lesson. This was evident during one of Teacher A's lessons in which I observed her students getting books from the reading corner and reading silently. Thereafter, the teacher and the students discussed what they had read. The literature contends that the function of reading is to comprehend written texts (Phajane, 2017). Teacher B's view of reading does not incorporate understanding and is thus missing an important element.

\section{Comparison of Teachers' Understanding of Teaching Reading}

The differences between the ways in which the two teachers teach reading, which reflects their underlying understanding of what it means to teach reading based on their experience as students. For example, in Teacher B's case unlike Teacher A, it might result from her own lack of reading exposure to books either at home or school as a young child. The other reason might be the context in which these two teachers find themselves. Teacher A's school is well resourced and has a reading culture when compared to Teacher B's school, which does not.

Makalela and Fakude (2014), argue that students in Grade 4 should read independently and automatically with understanding. In Teacher B's class this is not the case because students are still reading word by word without understanding, making it difficult for them to become independent readers. Consequently, students are not going to develop a love for reading, but rather have a shallow decoding view of reading. Students in Teacher B's class are unlikely to develop automaticity and become fluent readers (Makalela \& Fakude, 2014).

Both teachers were taught in a traditional and teacher-centred way involving phonics, rote learning and drilling. It is apparent that Teacher A's methods of teaching reading are consistent with her beliefs about learning to read. Similarly, Teacher B's practices are in line with her belief that reading is simply decoding without necessarily understanding. This may result from their different childhood experiences of reading. It could also be attributed to lack of explicit methods and strategies for teaching reading in the English Second Language Curriculum in Grade 4. What the curriculum stipulates is that students should: Read factual and fictional text in groups/pairs/individually; Recognize style and meaning; Skim text; Find and extract information from textbooks and books in the library. 
Teacher A tries to implement some of these strategies when teaching reading in her class as seen in her practice whereas Teacher B relies heavily on the teaching of phonics in her class, which should already have been dealt with in foundation phase grades. Sibanda and Baxen (2016), argue that: In most African countries, phonics instruction has been misused for teaching Language 2. Phonics is often associated with lists of both words unknown and used out of context. In such cases phonics become boring because emphasis is put on learning the letter relationship at the cost of understanding.

What Makalela (2010), claims, is evident in Teacher B's teaching using phonics. Furthermore, she struggles with phonics when the words she is dealing with are not of high frequency. For example, she confuses the vowel sounds in words like arrest, area and arrival, believing that because of their spelling they contain an 'ar' sound. It may be that she is not familiar with the pronunciation of these words and cannot hear the different phonemes. This is a problem for many teachers because English vowel sounds are difficult for speakers of African languages. This creates problems in the use of phonics, and it is an issue that needs to be addressed in teacher education. A comparison of the two teachers reveals the social structure reproducing itself. The relative advantages and disadvantages of Teacher A and Teacher B with regard to literacy are perpetuated in their beliefs, attitudes and the way they teach, and this continues to affect the children in their classes.

\section{DISCUSSION AND CONCLUSIONS}

The key findings of this study are derived from the interviews with participants, classroom observations and document analysis. What emerged strongly from these findings is that the way teachers teach is influenced by the context in which they find themselves, the curriculum, their beliefs, previous experience and the way they were trained to teach reading.

There were similarities and differences between the teachers. In the context of Teacher A's practice, it is observable that her past experience and her approach to the teaching of reading worked well with her class. Her school is well resourced in terms of reading books, both in her class and in the school library. As a child, Teacher A had access to many books at home in her mother tongue Setswana, the dominant language at the time.

In contrast, Teacher B who teaches in a rural school where few books are found and who has to rely on age inappropriate newspaper extracts, reveals less exposure to reading materials, less school support, as in lack of books and therefore poor practice. Setswana could be seen as an oppressed language which prior to independence had little economic or political value. These early experiences are reinforced by the kind of schools in which the two teachers find themselves.

Another finding is that although both teachers follow the curriculum, there are discrepancies in the way the curriculum is administered. For example, the approaches Teacher B uses in teaching reading are influenced by the way she was taught in the past. Teacher B makes heavy use of phonics on a daily basis in her teaching, whereas Teacher A uses a variety of teaching techniques when teaching reading. Therefore, the relative advantages and disadvantages of the two teachers with regard to literacy are perpetuated in their beliefs, attitudes and the way they continue to affect the children in their classes. From the teachers' interviews, it emerged that their practices are also led by their beliefs and training backgrounds.

The study further shows that both teachers were taught in a traditional, teacher-centered way involving phonics, rote learning and drilling. Because they see the value in the way they were taught and regard themselves as competent readers, they believe this approach had a good deal of value and it continues to affect the way they teach. Another factor which influences the way they teach is that neither of the teachers had received much in-service support on how to teach reading, so they were largely dependent on how they had learned to read themselves, on their pre-service teacher education and in the case of Teacher A, on a Molteno course.

In conclusion, the findings of this research are that teachers' practices are influenced by the way they were taught in the past, their formal training and the context in which they find themselves. Their beliefs shape and continue to affect the way they teach reading in their classrooms. The other factor that affects the teaching of reading is lack of in-service training on how reading should be taught in Grade 4 . It remains a challenge as neither of the teachers received any training or guidance on how to teach reading in Grade 4 nor had they benefited from in-service training except for Teacher A who had been on a Molteno course. The curriculum, too, provides little assistance in that it does not elaborate on the teaching approaches and strategies to be used when teaching reading.

Teachers should select relevant reading materials according to the level of the students. Subject Advisors should train and support teachers with relevant materials to enhance reading skills. Regular workshops on teaching reading should be done in schools. Teacher training institutions should ensure that teachers are well trained in the methods of teaching reading and interpretation of the curriculum. The 
curriculum should contain the methodology of teaching reading, (National Council for Curriculum and Assessment (NCCA) 2011), should monitor the implementation of the curriculum. The principals of the schools should be trained in curriculum implementation and note any changes that may appear in new or revised curricula. Since most students struggle with reading, more research is needed in this area to find out what proper educational intervention programmes could be put in place to assist students become better readers. We also need to investigate factors contributing to the students' struggle to become competent readers both in their first language and second language. Publishers should design materials that are relevant to students' interests and levels of understanding.

\section{REFERENCES}

Balc Bonacina-Pugh, F. (2017). Legitimizing multilingual practices in the classroom: the role of the 'practiced language policy', International Journal of Bilingual Education and Bilingualism, DOI: 10.1080/13670050.2017.1372359.

Caporal-Ebersold, E. (2018). Language Policy in a Multilingual Crèche in France: How is Language Policy Linked to Language Acquisition Beliefs (pp. 55-80). In M. Siiner, F. Hult, \& T. Kupisch (Eds.), Language Policy and Language Acquisition Planning. Cham, Switzerland: Springer.

Caporal-Ebersold, Eloise, \& Young, A. (2016). Negotiating and appropriating the 'one person, one language' policy within the complex reality of a multilingual crèche in Strasbourg. London Review of Education, 14(2), pp. 122-133. https://doi.org/10.18546/LRE.14.2.09.

Coxhead, A. (2016). Acquiring academic and discipline specific vocabulary. In K. Hyland, \& P. Shaw (Eds.), Routledge handbook of English for academic purposes (pp. 177-190). London: Routledge.

Cummins, J. (2012). The intersection of cognitive and sociocultural factors in the development of reading comprehension among immigrant students. Reading and Writing, 25(8), 1973- 1990.

Department of Basic Education (2014). Ministerial Task Team Report on the National Senior Certificate (NSC). Pretoria: Department of Basic Education.

Department of Education. (2012). Revised National Curriculum Statement for Languages. Overview. First Additional Language. Second Additional Language. Pretoria: DoE.

Diemer, M. N. (2016). The contributions of phonological awareness and naming speed to

the reading fluency, accuracy, comprehension and spelling of grade 3 isiXhosa readers. M A Thesis, Rhodes University.

Fakude, P.F. (2014). Reading comprehension trajectories in Sepedi: A case of rural Grade 7 students, South African Journal of African Languages,7 (1), 23-27.

Georgiana, C. (2012). Over-using mother tongue in English language teaching. Cultural and linguistic communication, 2 (3), 212-218.

International Reading Association (IRA). (2009). What is evidence-based reading instruction? A position statement of the International Reading Association. Newark, D.E: Author.

King, K., \& Lanza, E. (Eds.). (2017). Ideology, Agency, and Imagination in Multilingual Families. Special issue. International Journal of Bilingualism.

Makalela, L. (2010). Word and visual recognition among fourth graders: A simple view of reading in elementary schools: Conference proceedings on Language in Africa Symposium. Pretoria: CISR.

Makalela, L., \& Fakude, P.F. (2014). 'Barking' at texts in Sepedi oral reading fluency: Implications for edumetric interventions in African languages, South African Journal of African Languages, 31 (1), 71 78.

Maluch, J. T., Kempert, S., Neumann, M. \& Stanat, P. (2015). The effect of speaking a minority language at home on foreign language learning. Learning and Instruction, 36, 76-85.

Manyike, TV. (2017). The teaching of English in multicultural South African schools and its implications for teacher education. Series: Trends in Applied Linguistics, 26. Berlin \& Boston: De Gruyter. ISBN 9781-5015-0415-0.

Mitropolitski, S. (2015). Interactive interview. Forum Qualitative Sozialforschung/Forum: Qualitative Social Research 16(1): Article 8.

Modisaotsile, B. M. (2012). The failing standard of Basic Education in South Africa. Policy brief, AISA (Africa Institute of South Africa), Briefing 72, 1-7.

National Council for Curriculum and Assessment (NCCA). (2011). Better literacy and numeracy for children and young people: NCCA submission, February 2011. Dublin: Author.

National Education Evaluation and Development Unit (NEEDU). (2014). National Report 2014. Teaching and Learning in Rural Primary Schools. Pretoria: National Education Evaluation and Development Unit. 
Otto, B. (2014). Language development in early childhood education (4th Ed,). Upper Saddle River, New Jersey: Pearson Education, Inc.

Phajane, MH. (2017). Teaching the basics in the primary schools: Reading, writing and numeracy in Realigning Teacher Training in the 21st Century. Cengage learning. Edited by MD Magano, JC Mohapi and D Robinson. ISBN: 978-1-4737-3351-0.

Progress in International Literacy Studies (PIRLS) (2006). PIRLS 2006 International

Report. Retrieved on 30 August 2011 from www.pirls.bc.edu/pirls2006/intl_rpt.html.

Schwartz, M. (Ed.). (2018). Preschool Bilingual Education: Agency in Interactions Between Children, Teachers, and Parents. Dordrecht, Netherlands: Springer International Publishing. Retrieved from //www.springer.com/gp/book/9783319772271.

Sibanda J \& Baxen J. (2016). Determining ESL students' vocabulary needs from a textbook corpus: challenges and prospects. Southern African Linguistics and Applied Language Studies, 34(1):57-70. Doi: $10.2989 / 16073614.2016 .1159521$.

Statistics South Africa (Stats SA). (2016). Census 2011. Maps alive- Dominant home language. Pretoria: Statistics South Africa. http//: www.world-data-atlas.com/ statssa/\#. UMALUSI, (2014). Council for Quality Assurance in General and Further Education and Training. Developing a Framework for assessing and comparing the cognitive challenge of Home Language examinations. Pretoria: Umalusi. Vygotsky, L. S. (1995). Thought and language. Cambridge, MA: M.I.T. Press. 